\title{
Dietary patterns are associated with sexual maturation in Korean children
}

\author{
Shan Ji $\mathrm{Li}^{1}$, Hee Young Paik ${ }^{2}$ and Hyojee Joung ${ }^{3 *}$ \\ ${ }^{1}$ Human Ecology Research Center, Department of Food and Nutrition, Seoul National University, Seoul, Korea \\ ${ }^{2}$ Department of Food and Nutrition, Seoul National University, Seoul, Korea \\ ${ }^{3}$ The Graduate School of Public Health \& Institute of Health and Environment, Seoul National University, Seoul, Korea \\ (Received 22 August 2005 - Revised 18 November 2005 - Accepted 21 November 2005)
}

\begin{abstract}
The purpose of this study was to investigate the association between dietary patterns and sexual maturation among Korean children. A cross-sectional study was conducted in 422 boys and 365 girls aged 9-12 years living in Seoul, Korea. Three-day food records were obtained, and pubertal stages were determined with a questionnaire using Tanner stages. Body fat was measured by bioelectrical impedance analysis, and bone mass content at the right calcaneus was measured by portable dual-emission X-ray absorptiometry. Exploratory factor analysis with a Varimax rotation was applied to identify dietary patterns using twenty-four food groups. Four distinct dietary patterns - 'rice and Kimchi', 'shellfish and processed meat', 'pizza and drinks' and 'milk and cereal' - were obtained. Twenty-six per cent (24\% stage 2, $2 \%$ stage 3 ) of boys had genital development, and $79 \%(63 \%$ stage $2,16 \%$ stage 3$)$ of girls showed breast development. In boys, genital development was weakly positively associated with 'shellfish and processed meat' dietary factor scores (odds ratio $1 \cdot 65, \mathrm{CI} 0.95,2 \cdot 89, P$ for trend $0 \cdot 07$ ) after adjusting for confounders. In girls, breast development was significantly positively associated with the factor score of 'shellfish and processed meat' (odds ratio 1.88, CI 1.08, $3 \cdot 26, P$ for trend $0 \cdot 05$ ). These results suggest that dietary patterns were related to body composition and sexual maturation among the Korean children. Further investigations are needed to identify components of the foods consumed in high amounts in these patterns and how they are related to sexual maturation.
\end{abstract}

Sexual maturation: Dietary patterns: Children

The body size, shape and composition of children rapidly change in puberty, and nutrient intake, a major determinant of growth, is of great importance during that time (Rogol et al. 2002). Recent studies, including some from Korea, have reported that the average age of entering puberty is younger today than it was in the past, but differences between ethnic groups have been reported (Garn et al. 1986; Gerver et al. 1994; Park \& Kim, 1994; Herman-Giddens et al. 1997; Fredriks et al. 2000). Children with early sexual maturation may be at greater risk for diseases such as breast cancer, CVD, endometritic cancer, pancreatic cancer and osteoporosis in later life (Kelsey \& Bernstein, 1996; Petridou et al. 1996; Morrison et al. 1999; Wang, 2002).

Many researchers have investigated the possible reasons for early sexual maturation in children, including improved health and nutritional status, BMI and percentage body fat, and other factors such as socio-economic status, environment and physical activity (Meyer et al. 1990; Maclure et al. 1991. Malina et al. 1994; Koprowski et al. 1999; Kaplowitz et al. 2001; Koo et al. 2002).

In previous research on sexual maturation and pubertal age, the most consistent findings were the negative association of height, weight, BMI and percentage body fat with age at menarche in girls (Guo et al. 1998; Koprowski et al. 1999; Kaplowitz et al. 2001), and the negative association of BMI and percentage body fat with the onset of puberty in boys (Wang, 2002). Several studies have reported that single nutrients or foods influence sexual maturation, but results have been inconsistent regarding the specific nutrient levels among girls at onset of menarche (Meyer et al. 1990; Moisan et al. 1990; Maclure et al. 1991; Merzenich et al. 1993). For example, Britton et al. (2004) found that higher polyunsaturated fat consumption was positively associated with breast development and that vitamin $\mathrm{C}$ level was inversely related to pubic hair development. Other studies have reported that higher polyunsaturated fat (Maclure et al. 1991) and lower vitamin C consumption (Petridou et al. 1996) delayed menarche. Besides those nutrients, higher intakes of fibre, vitamin $\mathrm{A}, \mathrm{Fe}$ and thiamine have been associated with a later age at menarche (Hughes \& Jones 1985; Moisan et al. 1990; Koo et al. 2002). Furthermore, higher intakes of seeds and nuts were shown to have an inverse association with breast development (Li et al. 2004).

Earlier studies have focused mainly on the effects of single nutrients or foods with sexual maturation (Hill et al. 1980; Moisan et al. 1990; Merzenich et al. 1993; Koo et al. 2002). Foods and nutrients are, however, consumed in combination, and the combined effects can be observed only when the entire eating pattern is considered (Newby et al. 2003). No studies have yet examined the relationship between dietary 
pattern and sexual maturation. Therefore, the purpose of this study was to explore the association between dietary patterns and sexual maturation among Korean children in the early stages of puberty.

\section{Subjects and methods}

\section{Subjects}

The survey was conducted with 816 Korean students, aged 912 years old, who were attending the fourth and fifth grades of two elementary schools in Seoul, South Korea in May 2003. Data from 787 individuals $(96.4 \%)$ who successfully completed all components of the survey were used for analysis.

\section{Data collection}

Data collection included a 3-d food record, anthropometric measurements and a questionnaire to assess sexual maturation based on the Tanner stages. The questionnaire included socioeconomic information on the parents, such as their level of education, subjective economic status (high, middle, low) and job status.

During the first visit to the school, the trained project staff provided detailed instructions to the children on how to keep the 3-d (two weekdays and one weekend day) food records and how to select their Tanner stages on the questionnaire. We also sent a letter asking parents to assist their children with completing the dietary record and included instructions for the parents. We collected school lunch recipes and checked the amount of leftovers. School teachers helped the children to keep their diet records during class at school. The completed 3 -d food records and the questionnaire were collected at the second visit and reviewed by trained Korean dietitians. Incomplete or unclear food records were discussed with children using three-dimensional food models, cups and spoons.

At the second visit, anthropometric measurements including height, weight, body fat and bone mass were measured. Body fat mass, weight and height were measured by bioelectrical impedance analysis using the Inbody3.0 (Biospace Co. Ltd, Seoul, Korea), and bone mineral content (BMC) at the right calcaneus was measured by PIXI (Peripheral Instantaneous X-Ray Imager; Lunar Radiation Corp. Madison, WI, USA).

\section{Dietary pattern assessment}

Food items from the 3-d food records of each subject were aggregated into groups. Prior to the factor analysis, the food items were initially categorized into twenty-seven food groups, which were comparable to the food groups of the Korean Nutrition Society's Food Composition Database (Korean Nutrition Society, 2000). In a second step, three food groups were deleted, as their average amount of intake was less than $20 \mathrm{~g} / \mathrm{d}$. Thus, a total of twenty-four food groups were used for the dietary pattern analysis. The list of food groupings used in the dietary pattern analysis is shown in Table 1. We used the average amount of each of the twenty-four food groups consumed during the $3 \mathrm{~d}$. Average amounts were used because: (1) serving sizes are not commonly used in Korean dietary surveys; (2) the highest percentage of energy typically comes from the grain group; (3) the percentages of energy from the vegetable group are very low. The factors were rotated by orthogonal transformation (Varimax rotation function in SAS 8.1; SAS Institute Inc., Cary, NC, USA) to achieve a simpler structure with greater interpretability. In determining the number of factors to retain, we used the eigenvalue $>1.0$ criterion in the first step. This criterion is most widely used in factor analysis and is based on the fact that each factor retained should explain more variance than that of a single original variable in the dataset. This procedure created twelve independent factors in the present study, which was considered too large for further analysis. Thus, in the second step, we used the Scree plot and an eigenvalue of $>1 \cdot 25$. Four patterns remained and were used for this study.

\section{Statistical analysis}

Data were analysed using the Statistical Analysis System (SAS version 8.1, SAS Institute). We conducted exploratory factor analysis to identify major dietary patterns, and calculated the factor scores of each pattern for each individual. We tested the differences in body composition and nutrient intake between genders using the General Linear Model procedure after adjusting for age. The correlation between dietary patterns and body composition and nutrient intakes were calculated by partial Pearson correlation, including age as a covariate. The association between dietary patterns and sexual maturation was assessed using multiple logistic regression analysis by the factor score of the four dietary patterns.

\section{Results}

Although the ages of the boys and girls were similar, a higher percentage of girls indicated sexual maturation. Only $26 \%$ of the boys stated genital development, whereas $79 \%$ of girls stated breast development (Table 2). Mean BMI and BMC were significantly higher in boys than in girls after adjusting for age $(P<0 \cdot 001)$.

The four identified dietary patterns accounted for $29.2 \%$ of the total variation (Fig. 1). Factor loading is shown in Table 3. The first dietary pattern was termed 'rice and Kimchi'. In this group, green and yellow vegetables, garlic, white rice, meats, beans, bean products and vegetables showed the highest positive loading. The second dietary pattern showed a high loading for shellfish and processed meat; we called this group 'shellfish and processed meat.' The third dietary pattern was termed 'pizza and drinks'. In this group, carbonated drinks, pizza and hamburger, fruit and fruit juice, cookies and cakes showed the highest positive loading. The fourth dietary pattern was termed 'milk and cereal' and showed the highest positive loading for milk and yoghurt, cereal (breakfast cereal), other grains and fish.

The correlations between the dietary factor scores and body composition and nutrient intakes are presented in Table 4 after adjusting for age and energy intake. The 'shellfish and processed meat' dietary factor score was significantly positively associated with BMI and bone mineral density in boys $(P<0.05)$, but not in girls. After adjusting for age and energy intake, the 'pizza and drinks' dietary factor score was significantly positively associated with the percentage body fat and bone mineral density $(P<0 \cdot 05)$, and the 'milk 
Table 1. Food groupings used in the dietary pattern analysis

(Mean values and standard deviations)

\begin{tabular}{|c|c|c|c|}
\hline Food or food groups (g/d) & Mean & SD & Food items \\
\hline White rice & $329 \cdot 4$ & $105 \cdot 9$ & Rice \\
\hline Other grains & $42 \cdot 8$ & 35.9 & Barley, brown rice, black rice, rice cakes, foxtail millet \\
\hline Bread & $51 \cdot 8$ & $43 \cdot 0$ & Wheat flour, wheat products \\
\hline Noodles & $190 \cdot 4$ & $105 \cdot 6$ & Noodles, spaghetti, udong, Chinese noodle, wheat noodle \\
\hline Ramyon & $101 \cdot 9$ & $39 \cdot 2$ & Ramyon (a Korean instant noodle) \\
\hline Meat & $64 \cdot 1$ & $41 \cdot 2$ & Pork, beef, grilled beef with vegetable \\
\hline Processed meat & $44 \cdot 2$ & 21.4 & Pork cutlet, bacon, sausage, meat ball, ham \\
\hline Fish & $44 \cdot 4$ & $30 \cdot 9$ & $\begin{array}{l}\text { Hair tail, tuna, pacific cod, anchovy, Alaska pollock, } \\
\text { Spanish mackerel }\end{array}$ \\
\hline Shellfish & $44 \cdot 2$ & $26 \cdot 9$ & $\begin{array}{l}\text { Crab, oyster, whip-arm octopus, solen, warty sea squirt, } \\
\text { little neck clam, common squid, clam, hard-shelled mussel }\end{array}$ \\
\hline Poultry & $119 \cdot 7$ & $96 \cdot 4$ & Chicken, chicken breaded and fried, duck meat \\
\hline Eggs & $39 \cdot 3$ & $26 \cdot 2$ & Egg, quails egg, ducks egg \\
\hline Green and yellow vegetables & $32 \cdot 6$ & $20 \cdot 3$ & Green pepper, lettuce, spinach, chicory greens, sweet pepper \\
\hline Other vegetables and mushrooms & 39.9 & $22 \cdot 4$ & $\begin{array}{l}\text { Sweet potato stalk, bracken, oyster mushroom, Korean cabbage, } \\
\text { radish }\end{array}$ \\
\hline Potatoes & 31.4 & $39 \cdot 1$ & Potatoes, potato salad, potato chips \\
\hline Garlic and onion & $24 \cdot 7$ & $12 \cdot 9$ & Garlic, garlic - young stem, Welsh onion, onion \\
\hline Kimchi & 63.9 & $33 \cdot 3$ & $\begin{array}{l}\text { Korean cabbage, Yimu kimchi (leafy radish), small radish, } \\
\text { cucumber }\end{array}$ \\
\hline Pizza and hamburgers & $158 \cdot 4$ & $82 \cdot 1$ & Pizza, hamburger, hotdog \\
\hline Cookies and cakes & $70 \cdot 7$ & 44.5 & Snack, biscuit, cookies, cracker, cake \\
\hline Fruit and fruit juice & 233.7 & $168 \cdot 8$ & Fruits, fruit juice \\
\hline Milk and yoghurt & 288.5 & $128 \cdot 0$ & Milk, cheese, yoghurt \\
\hline Sweets and ice cream & $158 \cdot 7$ & $152 \cdot 6$ & Gum, starch syrup, candy, sugar, jelly, ice cream, sherbet \\
\hline Carbonated drink & 48.9 & $47 \cdot 6$ & Tea, carbonated drink, coffee, soda \\
\hline Beans and bean products & $41 \cdot 0$ & $38 \cdot 7$ & $\begin{array}{l}\text { Kidney beans, black soyabean, green peas, soyabean curd, } \\
\text { soyabean curd soft, soyabean curd fried, soyabean milk }\end{array}$ \\
\hline
\end{tabular}

For details of procedures, see p. 818.

Table 2. Characteristics of subjects by gender (Mean values and standard deviations)

\begin{tabular}{|c|c|c|c|c|}
\hline & \multicolumn{2}{|c|}{ Boys ( $n$ 422) } & \multicolumn{2}{|c|}{ Girls (n 365) } \\
\hline & Mean & SD & Mean & SD \\
\hline \multicolumn{5}{|l|}{ Body composition } \\
\hline Age (years) & $10 \cdot 22$ & 0.58 & $10 \cdot 23$ & 0.57 \\
\hline BMI $\left(\mathrm{kg} / \mathrm{m}^{2}\right)^{\star \star \star}$ & $19 \cdot 38$ & $3 \cdot 19$ & 18.03 & $2 \cdot 81$ \\
\hline Body fat (\%) & 23.56 & $7 \cdot 37$ & $22 \cdot 78$ & $7 \cdot 0$ \\
\hline $\operatorname{BMD}\left(\mathrm{g} / \mathrm{cm}^{2}\right)$ & 0.43 & 0.08 & 0.43 & 0.06 \\
\hline $\operatorname{BMC}(\mathrm{g})^{\star \star \star}$ & 1.61 & 0.39 & 1.47 & 0.29 \\
\hline \multicolumn{5}{|l|}{ Nutrient intake } \\
\hline Energy $(\mathrm{KJ})^{\star \star \star}$ & 7588 & 1808 & 6876 & 1474 \\
\hline Protein $(g)^{\star * *}$ & $69 \cdot 6$ & $14 \cdot 2$ & 62.9 & $10 \cdot 6$ \\
\hline Fat $(\mathrm{g})^{\star * *}$ & $54 \cdot 7$ & $12 \cdot 8$ & $49 \cdot 2$ & $10 \cdot 6$ \\
\hline Carbohydrate $(\mathrm{g})^{\star \star \star}$ & 258 & $45 \cdot 1$ & 236 & 33.6 \\
\hline $\mathrm{Ca}(\mathrm{mg})^{\star \star \star}$ & 577 & 171 & 534 & 133 \\
\hline $\mathrm{Fe}(\mathrm{mg})^{\star \star \star}$ & $9 \cdot 7$ & $2 \cdot 4$ & 8.9 & 1.7 \\
\hline Vitamin $A(R E)^{\star}$ & 597 & 155 & 573 & 104 \\
\hline Niacin $(\mathrm{mg})^{\star \star \star}$ & 14.9 & 3.9 & $13 \cdot 4$ & $2 \cdot 3$ \\
\hline Vitamin C (mg) & $63 \cdot 3$ & $24 \cdot 7$ & $61 \cdot 2$ & $23 \cdot 3$ \\
\hline $\mathrm{Zn}(\mathrm{mg})^{\star \star \star}$ & $8 \cdot 4$ & $1 \cdot 6$ & $7 \cdot 6$ & 1.5 \\
\hline Fibre $(g)^{\star \star}$ & 4.9 & $4 \cdot 8$ & $4 \cdot 2$ & $1 \cdot 3$ \\
\hline \multirow[t]{2}{*}{ Tanner stage } & Genital & Pubic hair & Breast & Pubic hair \\
\hline & $N(\%)$ & $N(\%)$ & $N(\%)$ & $N(\%)$ \\
\hline Stage 1 & $307(73)$ & $380(90)$ & $76(21)$ & $306(84)$ \\
\hline Stage 2 & $103(24)$ & $32(7 \cdot 6)$ & $229(63)$ & $49(13)$ \\
\hline Stage 3 or above & $7(2)$ & $5(1 \cdot 2)$ & $58(16)$ & $8(2)$ \\
\hline
\end{tabular}

$\mathrm{BMC}$, bone mineral content; $\mathrm{BMD}$, bone mineral density; RE, retinol equivalent.

Mean values were significantly different between genders by ANCOVA including age as a covariate. ${ }^{\star} P<0.05,{ }^{\star \star} P<0.01$, ${ }^{* \star *} P<0.001$.

For details of subjects and procedures, see p. 818 . 


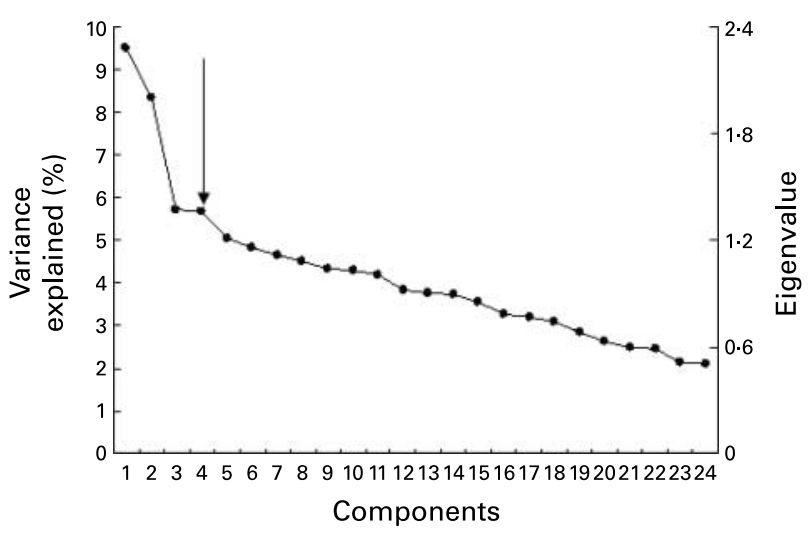

Fig. 1. Scree plot showing percentage of variance and eigenvalue explained by each component. $\downarrow$, indicates the cut-off point for dietary patterns. For details of subjects and procedures, see p. 818 .

and cereal' dietary factor score was significantly negatively associated with BMI and percentage body fat $(P<0.01)$ in girls, but not in boys. The 'rice and Kimchi' and 'milk and cereal' patterns were associated with most nutrient intakes, whereas the 'shellfish and processed meat' pattern was only associated with energy and niacin intake in girls and with energy, protein, fat, carbohydrate and niacin intake in boys.

The odds ratios (OR) and the $95 \% \mathrm{CI}$ of the stages of puberty of dietary pattern and body composition, genital stage 2 in boys and breast stage 2 and 3 in girls, are shown in Table 5. In boys, genital development was significantly negatively associated with percentage body fat (OR 0.96, CI 0.93, 0.99) and weakly positively associated with the factor score of 'shellfish and processed meat' (OR 1.65, CI 0.95, 2.89, $P$ for trend 0.07). In girls, breast development was significantly positively associated with percentage body fat (OR 1.05, CI 1.02 , 1.09), BMC (OR 6.06, CI 2.64, 13.9) and with the factor score of 'shellfish and processed meat' (OR 1.88, CI 1.08, 3.26, $P$ for trend $0 \cdot 05$ ).

\section{Discussion}

Using factor analysis, four distinct dietary patterns - 'rice and Kimchi,' 'shellfish and processed meat', 'pizza and drinks' and 'milk and cereal' - were identified from the 3-d dietary records obtained from 787 Korean children aged 9-12 years living in Seoul, Korea.

The four dietary patterns explained $29.2 \%$ of the total variation, which compares favourably with results previously reported. North \& Emmett (2000) identified four components from food-frequency data that explained $23.5 \%$ of the dietary variation in 3-year-old children. The four components identified by Whichelow \& Prevost (1996) using 1-week frequency dietary data from 18-81-year-old Americans accounted for $27.5 \%$ of the total variance, and the three components identified by Beaudry et al. (1998), obtained from the 24-h dietary recall data, accounted for $21.5 \%$ of the variance.

Several studies have reported that dietary pattern is associated with body composition in adults and the elderly. Maskarinec et al. (2001) reported that a high consumption of meat ('meat' pattern) was positively correlated with BMI and that 'vegetables', 'beans' and 'cold foods' were negatively related with BMI in Hawaiian women. Tucker et al. (2002) reported that a high intake of 'fruits, vegetables and cereals', along with $\mathrm{Mg}$ and $\mathrm{K}$, was associated with greater bone mineral density in older subjects of the Framingham Heart Study, aged 69-93 years. Among Hispanic elderly, the identified 'milk pattern' group had a significantly lower BMI (Lin et al. 2003).

The present study found that dietary patterns were associated with body composition in children. The boys with a higher score for the 'shellfish and processed meat' pattern (which is a more Westernized diet) had significantly higher BMI and body fat percentages after adjusting for age. On the other hand, girls with a higher score for the 'milk and cereal' pattern had significantly lower BMI and body fat percentages after adjusting for age, which is comparable to the study among Hispanic older adults, mentioned earlier. There

Table 3. Factor loading matrix for Korean children's diets*

\begin{tabular}{|c|c|c|c|c|c|}
\hline & Factor 1 & Factor 2 & Factor 3 & Factor 4 & $\%$ variance explained \\
\hline Green and yellow vegetables & 0.58 & & & & $36 \cdot 4$ \\
\hline Garlic & 0.56 & & & & $43 \cdot 8$ \\
\hline White rice & 0.54 & & & & $49 \cdot 3$ \\
\hline Meat & 0.39 & & & & $18 \cdot 3$ \\
\hline Beans and bean products & 0.37 & & & & $15 \cdot 5$ \\
\hline Vegetables & 0.36 & & & 0.33 & $27 \cdot 0$ \\
\hline Shellfish & & 0.75 & & & 57.5 \\
\hline Processed meat & & 0.73 & & & $54 \cdot 0$ \\
\hline Bread & & 0.47 & & & $24 \cdot 8$ \\
\hline Carbonated drinks & & & 0.68 & & $51 \cdot 1$ \\
\hline Pizza and hamburgers & & & 0.63 & & 44.9 \\
\hline Fruit and fruit juice & & & 0.41 & & $21 \cdot 3$ \\
\hline Cookie and cakes & & & 0.32 & & $13 \cdot 6$ \\
\hline Milk and yoghurt & & & & 0.61 & $44 \cdot 1$ \\
\hline Cereals & & & & 0.52 & $32 \cdot 3$ \\
\hline Fish & & & & 0.48 & 33.2 \\
\hline Eigenvalue & $2 \cdot 28$ & $2 \cdot 00$ & 1.37 & $1 \cdot 36$ & \\
\hline Percentage of variability & 9.51 & 8.35 & $5 \cdot 7$ & 5.67 & $\sum 29 \cdot 23$ \\
\hline Factor name & Rice and Kimchi & Shellfish and processed meat & Pizza and drinks & Milk and cereals & \\
\hline
\end{tabular}

${ }^{*}$ For simplicity, absolute factor loading values $<0.30$ were not listed in the table. 
Table 4. Partial correlation coefficients between dietary factor score and body composition and nutrient intake

\begin{tabular}{|c|c|c|c|c|}
\hline Dietary patterns & Rice and Kimchi & Shellfish and processed meat & Pizza and drinks & Milk and cereal \\
\hline \multicolumn{5}{|c|}{ Boys ( $n$ 422) } \\
\hline Body composition & \multicolumn{4}{|c|}{ Partial Pearson correlation including age as a covariate } \\
\hline BMI $\left(\mathrm{kg} / \mathrm{m}^{2}\right)$ & 0.03 & $0.134^{*}$ & 0.044 & -.0010 \\
\hline Body fat (\%) & -0.006 & $0.108^{*}$ & -0.011 & -0.010 \\
\hline $\operatorname{BMD}\left(\mathrm{g} / \mathrm{cm}^{2}\right)$ & -0.020 & 0.088 & 0.002 & 0.046 \\
\hline \multicolumn{5}{|c|}{ Partial Pearson correlation including age and energy as covariates } \\
\hline $\mathrm{BMI}\left(\mathrm{kg} / \mathrm{m}^{2}\right)$ & -0.012 & $0.108^{*}$ & 0.004 & -0.026 \\
\hline Body fat $(\%)$ & -0.036 & 0.094 & -0.038 & -0.023 \\
\hline $\operatorname{BMD}\left(\mathrm{g} / \mathrm{cm}^{2}\right)$ & -0.014 & $0.096^{\star}$ & 0.004 & 0.039 \\
\hline Energy and nutrients & \multicolumn{4}{|c|}{ Partial Pearson correlation including age as covariate } \\
\hline Energy (KJ) & $0.383^{* \star *}$ & $0.321^{\star * \star}$ & $0.416^{\star \star *}$ & $0 \cdot 276^{\star \star *}$ \\
\hline Fat $(g)$ & $-0 \cdot 192^{\star \star *}$ & $-0 \cdot 121^{\star *}$ & -0.026 & $0.194^{\star \star *}$ \\
\hline $\mathrm{Ca}(\mathrm{mg})$ & 0.002 & $0.094^{\star}$ & $-0.242^{\star * *}$ & $0.351^{\star * \star}$ \\
\hline $\mathrm{Fe}(\mathrm{mg})$ & $0.385^{\star \star \star}$ & -0.029 & -0.024 & $0 \cdot 209^{\star \star *}$ \\
\hline Vitamin A (RE) & $0.250^{\star \star \star}$ & -0.065 & 0.001 & $0.128^{\star \star}$ \\
\hline Niacin $(\mathrm{mg})$ & $0.337^{\star * \star}$ & $-0 \cdot 166^{\star * *}$ & -0.070 & $0.306^{\star \star *}$ \\
\hline Vitamin C (mg) & $0.262^{\star \star \star}$ & -0.039 & 0.093 & $0.175^{\star \star \star}$ \\
\hline $\mathrm{Zn}(\mathrm{mg})$ & $0 \cdot 225^{\star \star \star}$ & -0.085 & -0.079 & $0 \cdot 178^{\star * *}$ \\
\hline Fibre (g) & $0 \cdot 244^{\star \star \star}$ & 0.003 & $-0.172^{\star \star *}$ & $0 \cdot 125^{\star \star \star}$ \\
\hline \multicolumn{5}{|c|}{ Girls $(n 365)$} \\
\hline Body composition & \multicolumn{4}{|c|}{ Partial Pearson correlation including age as a covariate } \\
\hline BMI $\left(\mathrm{kg} / \mathrm{m}^{2}\right)$ & -0.084 & 0.046 & 0.061 & $-0.166^{\star \star}$ \\
\hline Body fat $(\%)$ & 0.029 & -0.026 & 0.067 & $-0 \cdot 182^{\star * *}$ \\
\hline $\operatorname{BMD}\left(\mathrm{g} / \mathrm{cm}^{2}\right)$ & -0.030 & -0.018 & 0.097 & -0.060 \\
\hline \multicolumn{5}{|c|}{ Partial Pearson correlation including age and energy as covariates } \\
\hline BMI $\left(\mathrm{kg} / \mathrm{m}^{2}\right)$ & -0.011 & 0.070 & 0.095 & $-0 \cdot 156^{\star \star}$ \\
\hline Body fat (\%) & 0.062 & 0.004 & $0 \cdot 112^{*}$ & $-0 \cdot 165^{\star \star}$ \\
\hline $\operatorname{BMD}\left(\mathrm{g} / \mathrm{cm}^{2}\right)$ & -0.031 & -0.014 & $0.117^{*}$ & -0.057 \\
\hline Energy and nutrients & \multicolumn{4}{|c|}{ Partial Pearson correlation including age as a covariate } \\
\hline Energy (KJ) & $0 \cdot 367^{* \star \star}$ & $0.333^{\star * *}$ & $0.416^{\star \star \star}$ & $0.276^{\star \star \star}$ \\
\hline Fat $(\mathrm{g})$ & $-0.283^{\star * *}$ & 0.002 & 0.089 & $0.194^{\star * *}$ \\
\hline $\mathrm{Ca}(\mathrm{mg})$ & 0.028 & 0.015 & $-0.297^{\star * \star}$ & $0.351^{\star * \star}$ \\
\hline $\mathrm{Fe}(\mathrm{mg})$ & $0.344^{\star \star \star}$ & -0.008 & -0.020 & $0.209^{* * *}$ \\
\hline Vitamin A (RE) & $0.134^{\star \star \star}$ & 0.050 & 0.087 & $0.128^{\star *}$ \\
\hline Niacin $(\mathrm{mg})$ & $0.209^{\star \star \star}$ & $-0.196^{\star \star *}$ & $-0.120^{*}$ & $0.306^{\star \star \star}$ \\
\hline Vitamin C (mg) & $0.275^{\star \star \star}$ & -0.009 & -0.021 & $0.175^{\star \star \star}$ \\
\hline $\mathrm{Zn}(\mathrm{mg})$ & $0.151^{\star \star \star}$ & $-0.121^{*}$ & -0.068 & $0.178^{\star \star \star}$ \\
\hline Fibre $(g)$ & 0.062 & 0.082 & $-0 \cdot 114^{\star \star *}$ & $0.125^{\star *}$ \\
\hline
\end{tabular}

$\mathrm{BMD}$, bone mineral density; RE, retinol equivalent.

${ }^{\star} P<0.05,{ }^{* \star} P<0.01,{ }^{* \star \star} P<0.001$.

For details of subjects and procedures, see p. 818

is limited information about the association between dietary patterns and body composition in children, so we were only able to compare our results with reports from the elderly. Our findings contribute to the limited body of evidence available for this target group.

We also examined the association between dietary pattern and sexual maturation, which was the purpose of the present study. To our knowledge, this is the first study that has examined the association between dietary patterns and sexual maturation in children. A causal relationship between dietary pattern and sexual maturation could not be determined because of the cross-sectional design of this study. However, a significant association between dietary pattern and sexual maturation remained after adjusting for age, percentage body fat and BMC. Although socio-economic status assessed using parental education, subjective economic status and employment status is known as a factor influencing pubertal maturation, we did not enter socio-economic status into the model as a confounder, because socio-economic status was not significantly different between the Tanner stages in both girls and boys in our study (data not shown).
In our results, the 'shellfish and processed meat' pattern was positively associated with sexual development in both boys and girl, after adjusting for confounders. The 'milk and cereal' pattern tended to be negatively associated with sexual development in girls after adjusting for confounders, but the association was weak and was not dose-dependent. Although it is not known whether diet influences sexual maturation in puberty, it is possible to speculate that dietary patterns affect body composition (e.g. body fat and BMI) and result in an early onset of pubertal maturation in children. Some longitudinal studies have suggested that early-maturing girls are more likely to be heavier and taller, and have a higher percentage of body fat and a greater BMI, than late-maturing girls of the same age (Guo et al. 1998; Kaplowitz et al. 2001; Rogol et al. 2002). Wang (2002) reported that early-maturing boys were less likely to be obese (OR 0.4 , CI $0 \cdot 2,0 \cdot 8$ ), whereas early-maturing girls were twice as likely to be obese. In this study, sexual maturation was negatively associated with the percentage of body fat in boys and was positively associated with the percentage of body fat in girls, which is consistent with the results of previous studies. 
Table 5. Adjusted odds ratios (OR) for sexual maturation for categories of dietary factor score - multiple logistic regression models*

(Mean values and standard deviations)

\begin{tabular}{|c|c|c|c|c|}
\hline & \multicolumn{2}{|c|}{ Factor score } & \multicolumn{2}{|c|}{ OR $(95 \% \mathrm{Cl})$} \\
\hline & Mean & SD & Boys & Girls \\
\hline \multicolumn{5}{|l|}{ Rice and Kimchi } \\
\hline T1 (low) & -1.02 & 0.44 & 1.00 & 1.00 \\
\hline $\mathrm{T} 2$ & 0.00 & 0.20 & $1.04(0.60,1.83)$ & $0.98(0.57,1.69)$ \\
\hline T3 (high) & $1 \cdot 31$ & 0.75 & $1.20(0.70,2 \cdot 67)$ & $0.85(0.50,1.46)$ \\
\hline$P$ for trend & & & 0.39 & 0.45 \\
\hline \multicolumn{5}{|c|}{ Shellfish and processed meat } \\
\hline T1 (low) & -1.07 & 0.33 & 1.00 & 1.00 \\
\hline $\mathrm{T} 2$ & -0.04 & 0.32 & $1.11(0.63,1.961)$ & $1.29(0.75,2.22)$ \\
\hline T3 (high) & $1 \cdot 14$ & 0.61 & $1.65(0.95,2.89)$ & $1.88(1.08,3.26)$ \\
\hline$P$ for trend & & & 0.07 & 0.05 \\
\hline \multicolumn{5}{|l|}{ Pizza and drinks } \\
\hline T1 (low) & -1.00 & 0.35 & 1.00 & 1.00 \\
\hline $\mathrm{T} 2$ & -0.20 & 0.22 & $1.14(0.65,2.01)$ & $0.82(0.48,1.41)$ \\
\hline T3 (high) & $1 \cdot 24$ & 0.88 & $1.30(0.75,2.26)$ & $0.90(0.52,1.53)$ \\
\hline$P$ for trend & & & 0.22 & 0.91 \\
\hline \multicolumn{5}{|l|}{ Milk and cereal } \\
\hline T1 (low) & -1.05 & 0.53 & 1.00 & 1.00 \\
\hline $\mathrm{T} 2$ & -0.03 & 0.24 & $0.99(0.56,1.75)$ & $0.44(0.25,0.78)$ \\
\hline T3 (high) & $1 \cdot 2$ & 0.77 & $1.07(0.62,1.86)$ & $0.61(0.35,1.06)$ \\
\hline$P$ for trend & & & 0.84 & 0.07 \\
\hline Age (years) & & & $1.10(0.72,1.68)$ & $2.34(1.54,3.56)$ \\
\hline Body fat $(\%)$ & & & $0.96(0.93,0.99)$ & $1.05(1.02,1.09)$ \\
\hline Bone mineral content (g) & & & $1.71(0.92,3.21)$ & $6.06(2.64,13.89$ \\
\hline Model $\chi^{2}$ & & & $13.96 P=0.234$ & $79.38 P<0.0001$ \\
\hline
\end{tabular}

* The test $\mathrm{P}$ for trend was calculated with mean values in each category as a continuous variable and adjusted for age, percentage fat and bone mineral content. The effect variables contain four dietary factor scores (categorical), age (continuous), body fat (continuous) and bone mineral content (continuous).

In the present study, the dietary factor score of the 'shellfish and processed meat' pattern was not associated with body composition in girls but was significantly positively associated with sexual maturation. Since fish consumption is high and the early onset of puberty is increasing in Korea, we can presume that contaminants such as dioxin/polychlorinated biphenyls and organochlorine, consumed with foods in this pattern, are possible factors contributing to the earlier onset of puberty (Blanck et al. 2000; Yoshida et al. 2000; Smith \& Gangolli, 2002).

The present study had several limitations, and the results should be interpreted with caution. First, cross-sectional data were used, and as a result causal association cannot be proven. Second, although the pictures of the Tanner stages were carefully explained to the children, sexual maturation was assessed by self-reporting. As the reliability and validity of the self-reported measures remains questionable, more accurate assessments of pubertal onset will be needed for future studies.

In brief, our study identified four dietary patterns derived from food-consumption data, and some dietary patterns were related to body composition and sexual maturation among Korean children. Our results support the idea that the dietary pattern during puberty may affect physical development and sexual maturation. Further investigation is needed to identify the components of the foods, including natural components and additives, which are consumed in high amounts within the identified patterns, and how they relate to sexual maturation.

\section{Acknowledgements}

This work was supported by grant No. R04-2002-000-20 0750 from the Basic Research Program of the Korea Science and Engineering Foundation.

\section{References}

Beaudry M, Galibois I \& Chaumette P (1998) Dietary patterns of adults in Quebec and their nutritional adequacy. Can J Public Health 89, 347-351.

Blanck HM, Marcus M, Tolbert PE, Rubin C, Henderson AK, Hertzberg VS, Zhang RH \& Cameron L (2000) Age at menarche and Tanner stage in girls exposed in utero and postnatally to polybrominated biphenyl. Epidemiology 11, 641-647.

Britton JA, Wolff MS, Lapinski R, Forman J, Hochman S, Kabat GC, Godbold J, Larson S \& Berkowitz GS (2004) Characteristics of pubertal development in a multi-ethnic population of nine-yearold girls. Ann Epidemiol 14, 179-187.

Fredriks AM, van Buuren S, Burgmeijer RJ, Meulmeester JF, Beuker RJ, Brugman E, Roede MJ, Verloove-Vanhorick SP \& Wit JM (2000) Continuing positive secular growth change in The Netherlands 1955-1997. Pediatr Res 47, 316-323.

Garn SM, LaVelle M, Rosenberg KR \& Hawthorne VM (1986) Maturational timing as a factor in female fatness and obesity. Am J Cli Nut 43, 879-883.

Gerver WJ, De Bruin R \& Drayer NM (1994) A persisting secular trend for body measurements in Dutch children. The Oosterwolde II Study. Acta Paediatr 83, 812-814.

Guo SS, Chumlea WC, Roche AF \& Siervogel RM (1998) Age and maturity related changes in body composition during adolescence 
into adulthood: the Fels longitudinal study. Appl Radiat Isot 49, $581-585$.

Herman-Giddens ME, Slora EJ, Wasserman RC, Bourdony CJ, Bhapkar MV, Koch GG \& Hasemeier CM (1997) Secondary sexual characteristics and menses in young girls seen in office practice: a study from the Pediatric Research in Office Settings network. Pediatrics 99, 505-512.

Hill P, Wynder EL, Garbaczewski L, Helman P, Hill M, Sporangisa J \& Huskisson J (1980) Diet and menarche in different ethnic groups. Eur J Cancer 16, 519-525.

Hughes RE \& Jones E (1985) Intake of dietary fiber and the age of menarche. Ann Hum Biol 12, 325-332.

Kaplowitz PB, Slora EJ, Wasserman RC \& Pedlow SE (2001) Earlier onset of puberty in girls: relation to increased body mass index and race. Pediatrics 108, 347-353.

Kelsey JL \& Bernstein L (1996) Epidemiology and prevention of breast cancer. Annu Rev Public Health 17, 47-67.

Koo MM, Rohan TE, Jain M, Mclaughlin JR \& Corey PN (2002) A cohort study of dietary fiber intake and menarche. Public Health Nutr 5, 353-360.

Koprowski C, Ross RK, Mack WJ, Henderson BE \& Bernstein L (1999) Diet, body size and menarche in a multiethnic cohort. $\mathrm{Br}$ J Cancer 79, 1907-1911.

Korean Nutrition (2000) Recommended Dietary Allowances for Korean. 7th Rev. Seoul, Korea: Joonang-Munhwa.

Li SJ, Paik HY \& Joung H (2004) Comparison of dietary intakes and body composition by Tanner stages in Korean girls. Korean J Nutr 37, 566-575.

Lin H, Bermudez OI \& Tucker KL (2003) Dietary patterns of Hispanic elders are associated with acculturation and obesity. J Nutr 133, $3651-3657$.

Maclure M, Travis LB, Willett W \& Macmaho B (1991) A prospective cohort study of nutrient intake and age at menarche. Am J Clin Nutr 54, 649-656.

Malina RM, Ryan RC \& Bonci CM (1994) Age at menarche in athletes and their mothers and sisters. Ann Hum Biol 21, 417-422.

Maskarinec G, Novotny R \& Tasaki K (2001) Dietary patterns are associated with body mass index in multiethnic women. $J$ Nutr 130, 3068-3072.
Merzenich H, Boeing H \& Wahrendorf J (1993) Dietary fat and sports activity as determinants for age at menarche. Am J Epidemiol 138, 217-224.

Meyer F, Moisan J, Marcoux D \& Bouchard C (1990) Dietary and physical determinants of menarche. Epidemiology 1, 377-381.

Moisan J, Meyer F \& Gingras S (1990) Diet and age at menarche. Cancer Causes Control 1, 149-154.

Morrison JA, Barton BA, Biro FM, Daniels SR \& Sprecher DL (1999) Overweight, fat patterning, and cardiovascular disease risk factors in black and white boys. J Pediatr 135, 451-457.

Newby PK, Muller D, Hallfrisch J, Qiao N, Andres R \& Tucker KL (2003) Dietary patterns and changes in body mass index and waist circumference in adults. Am J Clin Nutr 77, 1417-1425.

North K \& Emmett P (2000) Multivariate analysis of diet among three-year-old children and associations with socio-demographic characteristics. The Avon Longitudinal Study of Pregnancy and Childhood (ALSPAC) Study Team. Eur J Clin Nutr 54, 73-80.

Park HG \& Kim DH (1994) Physical growth according to sexual maturation of Korean adolescents. Korean J Pediat 37, 1187-1195.

Petridou E, Syrigou E, Toupadaki N, Zavitsanos X, Willett W \& Trichopoulos D (1996) Determinants of age at menarche as early life predictors of breast cancer risk. Int J Cancer 68, 193-198.

Rogol AD, Roemmich JN \& Clark PA (2002) Growth at puberty. J Adolesc Health 31, 192-200.

Smith AG \& Gangolli SD (2002) Organochlorine chemicals in seafood: occurrence and health concerns. Food Chem Toxicol 40, 767-779.

Tucker KL, Chen H, Hannan MT, Cupples LA, Wilson PW, Felson D \& Kiel DP (2002) Bone mineral density and dietary patterns in older adults: the Framingham Osteoporosis Study. Am J Clin Nutr 76, 245-252.

Wang Y (2002) Is obesity associated with early sexual maturation? A comparison of the association in American boys versus girls. Pediatrics 110, 903-910.

Whichelow MJ \& Prevost AT (1996) Dietary patterns and their associations with demographic, lifestyle and health variables in a random sample of British adults. Br J Nutr 76, 17-30.

Yoshida K, Ikeda S \& Nakanishi J (2000) Assessment of human health risk of dioxins in Japan. Chemosphere 40, 177-185. 